\title{
ABTÍ́CUIO DE RELISIÓN
}

\section{Nuevas tendencias de andamios en los procedimientos regenerativos endodónticos. Revisión bibliográfica}

\section{New scaffolding trends in regenerative endodontic procedures. Literature review}

\author{
Fernández Diana $^{1}$, Jiménez Liliana ${ }^{2}$ \\ ${ }^{1}$ Odontólogo. Especialista en Endodoncia. Universidad de Carabobo. Valencia, Venezuela. \\ ${ }^{2}$ Odontólogo Especialista en Endodoncia. Docente titular del Postgrado de Endodoncia de la \\ Facultad de Odontología, Universidad de Carabobo. Valencia, Venezuela. \\ dianafprotesis@gmail.com
}

\section{Resumen}

La regeneración endodóntica $(\mathrm{RE})$ se basa en el concepto de ingeniería tisular para restaurar el sistema de conductos a un estado saludable, buscando el desarrollo radicular continuo y del tejido circundante, e involucra componentes que incluyen células madre, factores de crecimiento y andamiajes, siendo estos últimos un elemento importante, sumamente estudiado. Definido como el soporte, vehículo de entrega o la combinación de materiales y biomoléculas con tecnología avanzada que facilitan la migración, unión y transporte celular. Exhibiendo beneficios como la estimulación para la producción de colágeno, diferenciación, proliferación y migración celular, angiogénesis, propiedades antibacterianas y antiinflamatorias. La presente investigación documental de diseño bibliográfico tuvo como objetivo analizar las nuevas tendencias de andamios dentro de los procedimientos regenerativos endodónticos (PRE), a través de la descripción del papel que juegan los diferentes componentes de la triada, enumerando, y explicando los beneficios de los diferentes andamios, y definiendo el de mayor ventaja. Basado en la revisión de artículos de revistas científicas indexadas, a través de la búsqueda electrónica en PubMed, ScienceDirect, Medline, Scielo y Google Académico; se consideró que la vascularización inadecuada, infección, procedimientos engorrosos, degradabilidad incierta, baja estabilidad, rigidez y resistencia representan un desafío importante. Conclusión: los concentrados plaquetarios de segunda generación, más recientes y optimizados (L-PRF y A-PRF) son las matrices que liberan mayor cantidad de plaquetas y factores de crecimiento, son de fácil preparación, presentan un mejor comportamiento del linaje fagocítico, disminuyen edema y dolor postoperatorio, aportando mejores resultados dentro de los PRE.

Palabras clave: regeneración endodóntica, células madre, PRP, concentrados plaquetarios, L-PRF, APRF. 


\section{Summary}

Endodontic regeneration (ER) is based on the concept of tissue engineering to restore the canal system to a healthy state, seeking continuous root development and surrounding tissue, and involves components that include stem cells, growth factors and scaffolds, being the latter an important element. Highly studied, defined as the support, delivery vehicle or the combination of materials and biomolecules with advanced technology that facilitate migration, binding and cell transport. Showing benefits such as stimulation for collagen production, cell differentiation, proliferation and migration, angiogenesis, antibacterial and antiinflammatory properties. The porpuse of this documentary research of bibliographic design was to analyze the new scaffolding trends within the endodontic regenerative procedures (ERP), through the description of the role played by the different components of the triad, enumerating, and explaining the benefits of different scaffolding, and defining the one with the greatest advantage. Based on the review of books and articles of indexed scientific journals, through electronic search in PubMed, ScienceDirect, Medline, Scielo and Google Scholar; considering inadequate vascularization, infection, tedious procedures, uncertain degradability, low stability, stiffness and resistance to be an important challenge. We concluded that the most recent and optimized second generation platelet concentrates (L-PRF and A-PRF) are the scaffolds that release more platelets and growth factors, are easily prepared, have a better phagocytic lineage behavior, decrease edema and postoperative pain, providing better results within the ERP.

Keywords: endodontic regeneration, stem cells, scaffolds, blood clot, PRP, platelet concentrates, L-PRF, A-PRF.

\section{Introducción}

Actualmente la RE es una alternativa y uno de los desarrollos más emocionantes en el área de endodoncia. A fin de solventar las principales desventajas de la terapia convencional. ${ }^{1}$

Los dientes con necrosis pulpar y ápices inmaduros pueden sufrir lesiones periapicales y en consecuencia estas condiciones dificultan la terapéutica endodóntica. Durante años el manejo tradicional ha sido mediante procedimientos de apicoformación o apexificación, ya sea a través de alternativa convencional a largo plazo con hidróxido de calcio [Ca $(\mathrm{OH}) 2]$ o, a través de la aplicación de una barrera apical con agregado trióxido mineral (MTA) y, más recientemente, el uso de nuevos biocerámicos como el Biodentine. $^{2}$

Sin embargo, ninguno de estos abordajes terapéuticos ha logrado la maduración apical, el grosor normal de las paredes radiculares y tampoco la regeneración de tejidos vitales en el espacio del conducto radicular, haciendo el diente susceptible a la fractura. En atención a ello actualmente, se emplean procedimientos regenerativos endodónticos que favorecen la permanencia de la unidad dentaria en boca. ${ }^{3}$

Dicho procedimiento involucra una serie de componentes que incluyen células madre, factores de crecimiento y andamiajes, siendo estos últimos un elemento importante que requieren de mayor investigación para el mejor desarrollo de la regeneración pulpar, que nos lleve a un tratamiento exitoso a largo plazo y por ende el mantenimiento del diente en boca. ${ }^{4}$

La presente investigación tuvo por objeto analizar las nuevas tendencias de andamios dentro de los procedimientos regenerativos endodónticos, a través de la descripción del papel que juegan los diferentes componentes de la triada de los procesos regenerativos 
endodónticos, enumerando, y explicando los beneficios de los diferentes andamios, para definir el andamio que ofrece mayores ventajas.

\section{Materiales y métodos}

La presente investigación documental estuvo basada en la revisión sistemática de diversas fuentes bibliográficas: libros y artículos de revistas científicas especializadas, encontrados a través de una búsqueda electrónica mediante el buscador PubMed, ScienceDirect, Medline, Scielo y Google Académico, enmarcados desde 1997 a 2019. Utilizando los términos regenerative endodontics, scaffolds in endodontics and pulp regeneration, reportando más de 300 artículos.

De los resultados de dicha búsqueda, se seleccionaron metaanálisis, revisiones bibliográficas, estudios prospectivos, reportes de caso, series de casos y algunos estudios in vitro e in vivo, los cuales debían cumplir con los siguientes criterios, (1) tener relación directa con el objetivo de la investigación, (2) resumen disponible y (3) acceso al artículo completo. Examinando un total de 140 artículos de los cuales se incluyeron 78; por tanto, se excluyen 62 artículos debido a que no estaban relacionados con los criterios establecidos de la investigación, referencias bibliográficas con más de 25 años de publicación y artículos donde no se encontraba definido el idioma original.

\section{Revisión Bibliográfica}

Los principios de la medicina regenerativa se pueden aplicar a la endodoncia con base en la ingeniería tisular. Entendiendo por la misma como un procedimiento cuyo objetivo es regenerar una pulpa funcional que genere nueva dentina y que sea capaz de responder a un estímulo. ${ }^{5,6}$
En otras palabras, la regeneración endodóntica utiliza el concepto de ingeniería tisular para restaurar los conductos radiculares a un estado saludable, lo que permite el desarrollo radicular continuo y del tejido circundante. ${ }^{3}$

Sin embargo, para que estas funciones se lleven a cabo se reconocen tres componentes necesarios, que son: a) las células madre b) las moléculas de señalización $o$ factores de crecimiento y c) un andamio o soporte físico que pueda apoyar el crecimiento y diferenciación celular. ${ }^{1,7,8,5,9}$

\section{Células madre}

Células indiferenciadas que cumplen un rol fundamental en la regeneración de los tejidos y en la capacidad de autoreparación del organismo, ya que permiten conformar estructuras biológicas complejas muy alejadas de las generadas por el clínico; como es el caso de tejidos duros presentes en el muñón pulpar y los tejidos periapicales ${ }^{10}$. Adicionalmente, la definen como una célula mesenquimática multipotente de origen postnatal, con propiedades paracrinas, capaz de dividirse continuamente y producir una progenie celular que puede diferenciarse en diversos tipos de células y tejidos, constituyendo lo que se conoce como diferenciación multilinaje. $^{11}$

En el mismo orden de ideas, las células madre en un principio están indiferenciadas, manteniendo su fenotipo hasta que son expuestas a una señal apropiada que estimula la diferenciación y de esta forma generan su función específica. ${ }^{5}$

Dentro de estas células se ubican las de la pulpa dental (DPSC), la de los dientes primarios exfoliados (SHED), de la papila apical (SCAP), del ligamento periodontal (PDLSC), las del folículo de la pulpa dental (DFSC), la de las glándulas salivales (SGSCs), las del epitelio oral (OESCs), las mesenquimales derivadas de la 
encía (GMSCs), las del germen dentario (TGPCs), las de la médula ósea (BMSC), las derivadas del periostio (PSCs) y las hematopoyéticas (HSCs) ${ }^{12-15}$. (Fig. 1)

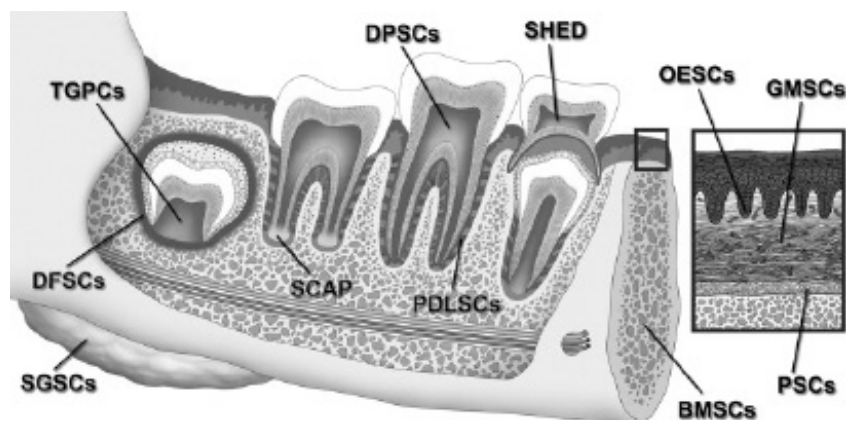

Figura 1. Avances en bioingeniería dental y su aplicación en ortodoncia y ortopedia dentofacial: Una revisión de literatura. Tomado de Caicedo C. ${ }^{14}$

\section{Factores de Crecimiento}

También conocidas como proteínas extracelulares o polipéptidos que al unirse a su receptor modulan funciones, mantienen la supervivencia celular y estimulan a la migración, proliferación, diferenciación y apoptosis, hacia fenotipos angiogénicos, neurogénicos y de mineralización, controlando el ciclo celular. ${ }^{15,14}$

Se destacan los factores de crecimiento fibroblástico (FGF), de crecimiento transformante beta (TGF- $\beta$ ), proteínas morfogenéticas óseas (BMPs), derivado plaquetario (PDGF), angiogenina angiopoyetina1 (ANG-1), proteína inflamatoria de macrófago2 (MIP-2), insulínico (IGF), vascular endotelial (VEGF) y de necrosis tumoral (TNF). Entendiendo que estos factores no sólo se encuentran en la papila apical sino también en la matriz extracelular dentinária (ME). ${ }^{16,17}$

Adicionalmente pueden derivar de células residentes (interacciones paracrinas), y tejidos mineralizados circundantes ${ }^{10}$. La dentina por si sola ha sido reconocida como la mayor fuente de señales morfogenéticas que modulan los procesos de la dentinogénesis reparativa y reaccionaria. Estas proteínas pueden movilizarse por la desmineralización dentinária observada durante la progresión de una caries. Asimismo, el EDTA los puede liberar debido a su acción quelante. El hidróxido de calcio utilizado para el recubrimiento pulpar directo puede liberar estos factores de crecimiento que tienen potencial regenerativo. ${ }^{18}$

\section{Andamios}

Matriz extracelular que genera la inducción permisiva o soporte estructural a las células involucradas en la regeneración del tejido afectado, a fin de dirigir el crecimiento celular y facilitar la formación de las células y tejidos adyacentes ${ }^{19}$. Por su parte, la Asociación Americana de Endodoncia lo define como una red que proporciona un marco para que las células madre crezcan y ocurra la regeneración pulpar. ${ }^{4}$

Adicionalmente, los andamios incorporan señales biológicas que les permiten actuar como una plataforma bioactiva para controlar con precisión el comportamiento de las células madre para su crecimiento y diferenciación, promoviendo la adhesión y migración. ${ }^{20}$

La matriz o andamio debe reunir los siguientes requisitos: 1.- ser biocompatible, 2.- altamente poroso 3.- físicamente resistente 4.- tener capacidad de reemplazo 5.- poseer propiedades mecánicas para soportar la reconstrucción de defectos 6.- proporcionar una posición correcta de la ubicación celular 7.- promover las interacciones celulares-biomateriales, la adhesión celular y la deposición de ME 8.provocar un grado mínimo de inflamación o toxicidad in vivo 9.- contar con una microarquitectura para la distribución del estrés 
10.- ser osteoinductor para la diferenciación osteogénica 11.- permitir el transporte de nutrientes, gases y factores reguladores, así como, propiedades en su superficie que permitan la supervivencia, proliferación y diferenciación celular 12.- debe ser plástica para adaptarse con facilidad a las formas estructurales 13.- debe proporcionar un soporte mecánico para mantener un espacio acorde al tejido en formación y permitir una correcta distribución y flujo de células 13.- la interacción superficial andamiocélulas debe permitir el crecimiento y mantener la función de las células diferenciadas y del tejido circundante. ${ }^{15,21-23}$

En el caso de estar constituida por biomateriales, debe ser fácilmente esterilizable y tener la habilidad para coexistir e interactuar en la presencia de tejidos específicos o sistemas fisiológicos como sangre, fluidos intersticiales, moléculas y células inmunes sin infligir un daño intolerable. Luego de la degradación del sustrato biomaterial, debe quedar, en el lugar, un tejido totalmente normal. ${ }^{15,19}$

Resulta importante señalar que los andamios varían ampliamente; según su estructura $\mathrm{y}$ arquitectura, pueden ser fibrosos o esponjosos con un tamaño de poro y porosidad variable. ${ }^{24}$ En función a sus propiedades, los andamios pueden tener administración variable de fármacos, comportamiento celular, comportamiento in vivo $\mathrm{y}$ propiedades biofisicomecánicas distintas. ${ }^{12}$

Actualmente se han diseñado andamios inteligentes con la incorporación de moléculas bioactivas, nanopartículas y el uso de modificaciones personalizadas de las propiedades físicas y químicas. Las deficiencias típicas de los andamios tradicionales incluían infecciones relacionadas con el material, fallas mecánicas y reacciones inmunológicas adversas con el huésped. Por lo que en estudios recientes se ha propuesto desarrollar construcciones novedosas de andamios inteligentes que instruyen e inducen efectos en las células para mejorar la eficacia de la regeneración de tejidos. ${ }^{24,25}$

\section{Clasificación de los andamios}

De acuerdo a su origen se dividen en naturales, sintéticos e híbridos (Tabla 1).

Tabla 1. Clasificación de los andamios de acuerdo a su origen

\begin{tabular}{lll}
\hline \multicolumn{1}{c}{ Naturales } & Sintéticos & Híbridos \\
\hline $\begin{array}{l}\text { Coágulo de Sangre } \\
\text { Membrana }\end{array}$ & PGA & Hidrogeles \\
Colágena & PLA & \\
Chitosan & PCL & \\
Ácido Hialurónico & Cerámico & \\
& Bioactivo & \\
Membrana & Vidrio & \\
Amniótica & Bioactivo & \\
Alginato & & \\
\hline
\end{tabular}

PGA: Ácido poliglicólico; PLA: Ácido Poliláctico; PCL: Policaprolactona

\section{Beneficios de los andamios}

Los andamios exhiben una serie de beneficios, entre ellos:

Reservorio rico en factores de crecimiento, promueve las condiciones para el desarrollo de paredes dentinárias en tercio medio apical ${ }^{26-28}$, son biocompatibles y bioactivos, no inducen respuesta inflamatoria, no inmunogénico, y no trombogénico ${ }^{19,29-31}$.

Ofrece un escenario favorable para el crecimiento de nuevos vasos sanguíneos ${ }^{32}$, induce la diferenciación celular osteogénica de las SCAP y odontogénica de las DPSC y fibroblastos $^{21,25-27,33,34}$, presenta actividad antimicrobiana y son osteoinductores ${ }^{35}$, ofrecen rigidez, alta resistencia a la deformación y a la fractura $^{20,21,27,34,36}$. Pueden combinarse con otras 
matrices para evitar el colapso del MTA y estabilizar el coagulo de sangre ${ }^{37,28}$, y por último exhiben una adecuada porosidad para el transporte de nutrientes y factores reguladores. ${ }^{31}$, 38,39

\section{Nuevas tendencias en andamios dentro de los procedimientos regenerativos endodónticos (PRE)}

\section{Plasma Rico en Plaquetas (PRP)}

Es un volumen de plasma autólogo con alta concentración de plaquetas (1millón/ml) utilizada en la regeneración endodóntica gracias a sus características ideales en cuanto al soporte, diferenciación, proliferación celular y adaptación tridimensional al conducto radicular $^{1,7}$. Asimismo, otros estudios refieren que es rica en factores de crecimiento como el factor derivado plaquetario, el factor transformante beta, el factor de insulina, el factor de crecimiento endotelial, el factor de crecimiento epidérmico y epitelial. ${ }^{7}$ Estos son liberados por medio de la degranulación de los gránulos alfa y juegan un rol importante en los procesos de regulación celular como la mitogénesis, quimiotaxis, diferenciación y metabolismo que, a su vez, estimulan la reparación ósea $\mathrm{y}$ de tejidos blandos. ${ }^{1,31,40}$

\section{Fibrina rica en plaquetas (FRP)}

Es la segunda generación de concentrado plaquetario adaptado a una preparación simplificada sin procedimiento bioquímico de manejo de sangre. Fue desarrollado por Choukroun et al en el año 2001 para el área de cirugía bucal y maxilofacial. A través de un protocolo de polimerización gradual que incorpora grandes concentraciones de citocinas en la fibrina. Dando como resultado un producto de tres capas:

1.-Plasma pobre en plaquetas acelular en la parte superior.
2.-Coágulo de sangre con fibrina rica en plaquetas en la parte intermedia.

3.- Fracción roja de sangre de células sanguíneas en la base.

Debido a la consistencia sólida de la fibrina, es lentamente destruida por remodelado, similar al coágulo de sangre natural. Dependiendo del envío continuo y local de una amplia gama de factores de crecimiento como el factor transformante beta, el factor derivado plaquetario y el factor de crecimiento vascular y endotelial en conjunto con una glicoproteína coagulada matricelular (TSP-1) promueven el proceso de regeneración y reparación de tejidos durante un periodo de 7-28 días. Recientemente, la FRP ha sido utilizada como andamio para ingeniería tisular y regeneración de varios tejidos como el perióstico, ligamento periodontal, tejido blando maxilofacial, pulpa dental y tejido del miocardio. ${ }^{12,41,42}$

Por consiguiente, sus ventajas sobre el plasma rico en plaquetas provienen de su fácil preparación y que no es necesaria la adición de un material anticoagulante que sea resultado de una sustancia natural y autogénica. ${ }^{12,43}$ (Fig. 2)

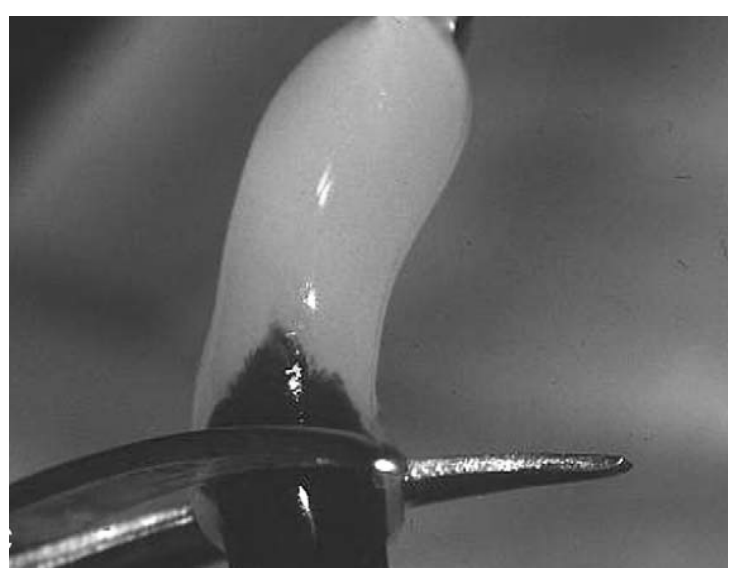

Figura 2. Fibrina rica en plaquetas (FRP): un concentrado de plaquetas de segunda generación. Parte I: conceptos tecnológicos y evolución. Tomado de Dohan D. ${ }^{43}$ 


\section{Fibrina Rica en Plaquetas y Leucocitos (L- PRF)}

Constituyen biomateriales de fibrina sólidos con leucocitos respectivamente. Se produce sin la adición a la sangre extraída de sustancias activadoras, dando lugar a una estructura de fibrina fuerte. ${ }^{44}$

También se define como un coágulo de sangre autógeno optimizado, del que se obtiene una membrana de fibrina fuerte, formada por células autógenas y enriquecida con factores de crecimiento y proteínas de la matriz ${ }^{44}$. Su técnica de obtención consiste en la extracción de $10 \mathrm{ml}$ de sangre de la vena antecubital del paciente (aunque en ocasiones nos veremos obligados a canalizar otra vena) y su inmediata centrifugación sin anticoagulantes a $3.000 \mathrm{rpm}$ durante $10 \mathrm{~min}$ o a $2.700 \mathrm{rpm}$ durante $12 \mathrm{~min}^{44}$

Algunos autores recomiendan aumentar la velocidad de centrifugación en pacientes anticoagulados hasta $18 \mathrm{~min}$. Cada tubo de extracción sanguínea equivaldrá a una membrana de L-PRF. ${ }^{44}$

El coágulo de L-PRF contiene un $97 \%$ de plaquetas y más de un $50 \%$ de los leucocitos del coágulo inicial (así como linfocitos), dando lugar a una matriz fuerte de fibrina con una distribución tridimensional específica capaz de liberar factores de crecimiento y proteínas implicadas en la curación de heridas durante más de 7 días in vitro, promoviendo la proliferación y diferenciación celular. ${ }^{44}$

Asimismo, posee un gran potencial de regeneración natural, acelerando la curación tanto de tejidos blandos como duros. Además, disminuye el edema y el dolor postoperatorio en el paciente, lo que mejora su grado de satisfacción con el tratamiento. ${ }^{44}$

Sin embargo, presenta como limitante el factor tiempo que transcurre desde la obtención de membrana de L-PRF hasta su inserción en el lecho quirúrgico, ya que debe realizarse de forma inmediata porque una vez que la sangre entra en contacto con las paredes del tubo de ensayo comienza a coagularse, una polimerización difusa que conduce a la obtención de un coagulo sin consistencia. Es por ello que hoy en día se crean las cajas quirúrgicas de L-PRF que pueden retrasar hasta tres horas la inserción de las membranas ya preparadas siempre y cuando permanezcan en el interior de la misma hasta que llegue el momento de su uso. ${ }^{45}$

\section{Fibrina rica en plaquetas avanzadas (A-PRF)}

Considerado como biomateriales autólogos (Choukroun et al. 2001). Representan una generación más reciente de concentrados de plaquetas $^{44,46}$. (Fig. 3)

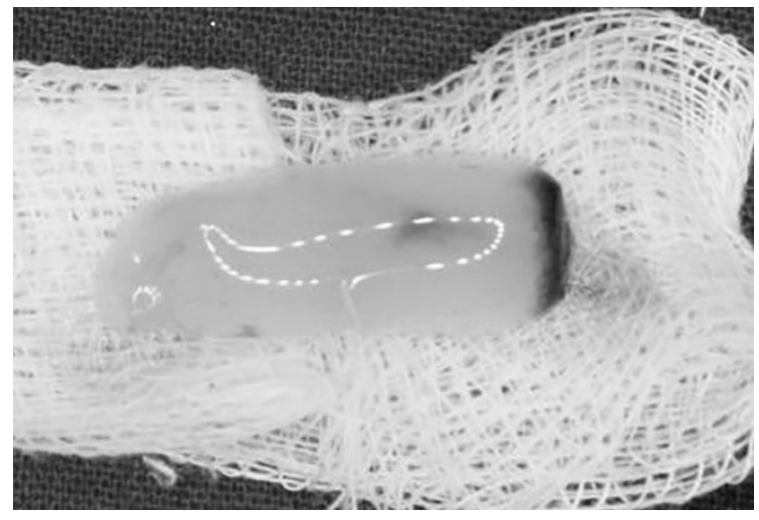

Figura 3. Comparación de dos técnicas quirúrgicas en el tratamiento de múltiples recesiones gingivales intercaladas con una combinación de A-PRF y L-PRF. Tomado de Sameera S. ${ }^{46}$

Se obtiene a través de un nuevo protocolo donde se han modificado los procedimientos de centrifugación para mejorar aún más la regeneración de tejidos. Mientras que la FRP estándar se centrifuga a $2700 \mathrm{rpm}$ durante 12 min, la A-PRF se centrifuga a velocidades más bajas (1500 rpm, $14 \mathrm{~min})$. La modificación del 
protocolo de centrifugación ha dado como resultado el aumento del número plaquetas y el mejor comportamiento del linaje celular fagocítico como lo son los monocitos y macrófagos, así como, mayor cantidad de células progenitoras vivas en comparación con la FRP, por lo que el aumento significativo subsiguiente en la liberación total de proteínas puede presentar ventajas adicionales para el uso clínico. $^{47}$

También se evidenció que los protocolos de centrifugación más lento de A-PRF liberaran más factores de crecimiento como PDGF-BB, VEGF y TGF- $\beta 1$ en comparación con la FRP convencional y puede ser clínicamente beneficiosa para futuros procedimientos regenerativos. ${ }^{48,47}$

\section{Discusión}

Los andamios son un elemento clave y sumamente estudiado por lo que ha generado avances en las nuevas tendencias para estos procedimientos. Asimismo, no existe un consenso en relación a la matriz adecuada que debe utilizarse para los PRE. Aunque el coágulo de sangre (CS) es un buen andamio, Banchs y Trope 2004 enfatizan que para una adecuada revascularización es necesario visualizar radiográficamente $1.1 \mathrm{~mm}$ de amplitud a nivel del ápice radicular. ${ }^{49}$ Por su parte, Wigler et al. afirman que el CS contiene sólo un 5\% de plaquetas como fuente de factores de crecimiento, $94 \%$ de eritrocitos y $1 \%$ de glóbulos blancos ${ }^{50}$. Estudios como los de Nosrat, Lenzi et al. en el 2012 plantearon la hipótesis de que el CS podría no ser lo suficientemente estable como andamio para soportar el proceso de regeneración de tejidos en sus fases iniciales $^{51,52}$. Namour alega ser esencial en cualquier procedimiento regenerativo un sistema inmune de calidad, una desinfección profunda y un sellado coronal y apical para que no ocurra una recontaminación ${ }^{53}$. Sin embargo, Alshehadat et al. aseveran exhibir limitaciones debido a que la composición del coágulo es variable ${ }^{36}$. Devillard, Lambrichts y Facchin $\mathrm{C}$ et al. certifican lo anteriormente expuesto y a su vez avalan ser necesario un diámetro mínimo ( $1 \mathrm{~mm})$ para obtener un flujo sanguíneo suficiente para la migración celular. ${ }^{11,37,54}$

Ding, Cehreli, Mc Cabe y más recientemente Ulusoy A et al. 2019 ratifican que la inducción al sangrado apical o para lograr un volumen sanguíneo adecuado dentro del espacio del conducto radicular sigue siendo un problema común. Así como también, alegan que la concentración de factores de crecimiento es limitada. ${ }^{55-58}$

Adicionalmente, Jung et al. resaltan la desventaja estética que presenta el CS después de estar en contacto con el MTA y a su vez aseveran que la matriz de colágeno evita el colapso o desalojo del MTA, promoviendo el crecimiento de tejido en el interior del espacio pulpar $^{59}$. Chan y Galler contraindican su uso en endodoncia regenerativa por no tener adecuadas propiedades mecánicas, limitando su aplicabilidad en estudios in vivo ${ }^{60,61}$. No obstante, Petrino y Diogenes et al. afirman que la adición de una matriz de colágeno al CS ayudaría con la colocación óptima de MTA y de esta forma evitar cambios de coloración en la unidad dentaria. ${ }^{62,63}$

Por su parte, Jiang asevera que un aumento de grosor de la pared dentinaria en tercio medio radicular, trae como ventaja mayor resistencia a la fractura cervical. No obstante, se refuta el uso de esta matriz por el hecho de que ocurre muy poco desarrollo radicular ${ }^{28}$. Años más tarde, Moyetones et al. certifican que el problema estético se debe al contacto de la sangre con la pasta triple antibiótica y el MTA. ${ }^{64}$

Ante estas desventajas inicia una nueva era de concentrados plaquetarios. Torabinejad et al. resaltan que PRP presenta una fuente abundante 
de factores de crecimiento y un recuento plaquetario cinco veces mayor en comparación al $\mathrm{CS}^{65}$. Asimismo, Bezgin et al. reportan estudios donde el cierre apical completo es de 8.1 meses para PRP y 9 meses para CS e infieren que el incremento del área radicular es de 9,86\% para CS y $12,6 \%$ para PRP. ${ }^{25}$ No obstante, Anantula et al. manifiestan que se requiere de dos procesos de centrifugado y la adición de trombina y/o cloruro de calcio. ${ }^{41}$

Clínicamente, la capacidad de PRP para crear tejido vital y coagular en el conducto radicular es relativamente más rápida que $\mathrm{el} \mathrm{CS}$, que necesita unos 15 minutos. Además, para los PRE durante el uso de PRP no es necesaria la aplicación de la anestesia local, es fácil de aplicar, tiene mejor consistencia y es más adecuado para la posterior colocación de agregado de MTA y restauración permanente $^{36}$. No obstante, Orión et al. confirman que la técnica es engorrosa y lenta. ${ }^{44}$

Actualmente, se han empleado fibrina rica en plaquetas, fibrina rica en plaquetas y leucocitos y fibrina rica en plaquetas avanzadas, alcanzado resultados prometedores en lo que se refiere a la regeneración confiable y predecible del complejo dentino-pulpar. ${ }^{66}$

Dohan et al. confirman que la técnica para la obtención de FRP no requiere de anticoagulantes, aditivos y no más de un proceso de centrifugado, permitiendo así, la activación de un mayor número de plaquetas ${ }^{43}$. Por su parte, Gassling et al. asociaron el L-PRF con resultados positivos en la reparación y regeneración del tejido óseo ${ }^{67}$. Anantula en acuerdo con lo anteriormente expuesto, indican que FRP presenta ventajas sobre el PRP por su fácil preparación, aplicación y bajo costo. ${ }^{41}$

Al mismo tiempo Alshehadat et al. establecen que la FRP presenta beneficios como la liberación lenta de los factores de crecimiento durante un período prolongado de 7-14 días ${ }^{36}$. Sin embargo, He et al. afirman que no puede inyectarse debido a que es una matriz sólida ${ }^{42}$. Posteriormente, Zhou determina que no hay diferencias significativas en la utilización FRP y CS en conjunto o de forma individual. ${ }^{68}$

La L-PRF contiene un $97 \%$ de plaquetas y más de un $50 \%$ de los leucocitos del coágulo inicial (así como linfocitos), dando lugar a una matriz fuerte de fibrina con una distribución tridimensional específica capaz de liberar niveles más altos de factores de crecimiento y proteínas implicadas en la curación de heridas durante más de 7 días in vitro, promoviendo la proliferación y diferenciación celular ${ }^{21,44}$. Años más tarde Kobayashi, Miron y Dragonas $\mathrm{P}$ confirmaron que la L-PRF mejora la cicatrización de heridas en tejidos blandos al promover la angiogénesis y la proliferación celular. ${ }^{47,69,70}$

Crisci et al. concluyen que los neutrófilos, macrófagos y plaquetas presentes en dicha matriz son elementos clave en la curación de heridas $\mathrm{y}$, en combinación con sus factores de crecimiento / citoquinas secretadas, pueden facilitar la regeneración tisular, la formación de nuevos vasos sanguíneos (angiogénesis) y la prevención de infecciones. $^{71}$

Sharma et al. ratifican el gran potencial de regeneración natural que tiene A-PRF, acelerando la curación tanto de tejidos blandos como duros. Además, disminuye el edema y el dolor postoperatorio en el paciente, lo que mejora su grado de satisfacción con el tratamiento $^{72}$. Por otra parte, Ghanaati $\mathrm{S}$ et al. 2014 aseveran que las células se distribuyen más uniformemente en el coágulo que L-PRF. ${ }^{73}$

Kobayashi y Sameera et al. definen que el APRF se obtiene a través de un nuevo protocolo donde se han modificado los procedimientos de centrifugación para mejorar aún más la regeneración tisular, dando como resultado el aumento del número plaquetas y el mejor comportamiento del linaje celular fagocítico, así como, mayor cantidad de células progenitoras 
vivas. Asimismo, se evidenció liberación de mayor cantidad de factores de crecimiento como, PDGF-BB, VEGF y TGF- $\beta 1$ en comparación con la FRP convencional y puede ser clínicamente beneficiosa para futuros procedimientos regenerativos. ${ }^{47,46}$

Paralelamente Gathani et al. afirman que los andamios biocerámicos tienen una fabricación que requiere mucho tiempo, falta de fase orgánica, tamaño $\mathrm{y}$ forma de partículas no homogéneas, gran tamaño de grano, difícil control de la porosidad, dificultad de conformación, fragilidad, tasa de degradación lenta y alta densidad por lo que recomiendan utilizarlo en combinación con otro andamio como por ejemplo los que son a base de polímeros. $^{21}$

En ese orden de ideas, polímeros biodegradables como el PGA mejoraron el crecimiento de nuevos vasos sanguíneos y la diferenciación odontogénica de los fibroblastos. Sin embargo, estudios in vivo e in vitro realizados por Aleshadat et al. aseveran que el andamio de colágeno (esponja) es superior al PGA para propósitos de ingeniería tisular dental al utilizar DPSC porcina. Mientras, que el vidrio bioactivo (BG) es capaz de apoyar la osteogénesis y proangiogénesis. Y su degradación libera iones que contribuyen en la osteogénesis y angiogénesis.

Por otra parte, la PCL es un andamio de múltiples aplicaciones, utilizado en varias áreas de la salud, que induce al crecimiento y diferenciación celular sin necesidad de factores de crecimiento $^{36}$. Kim et al. afirman que la mineralización o hidrogel a base de PCL es muy atractiva para la regeneración del tejido dentinário al inducir el crecimiento $\mathrm{y}$ la diferenciación odontogénica de las $\operatorname{DPSC}^{74}$. Sin embargo, Keller et al. atestiguan que el largo proceso de fabricación, así como la incorporación limitada de nanofibras son el mayor inconveniente del uso de hidrogeles. ${ }^{75}$
Gathani, Bolaina y Conte también han señalado desventajas de la PCL, entre ellas, lenta degradación, baja resistencia a la tracción y efecto hidrófobo. Sin embargo, su biocompatibilidad, alta resistencia a la fractura y la adición de polímeros naturales contrarrestan estos inconvenientes y lo convierten en una matriz con un futuro prometedor en ingeniería tisular. ${ }^{21,34,76}$

Zein et al. alegan que hidrogeles a base de chitosan tiene una característica policatiónica que les confiere propiedades hemostáticas y antimicrobianas $^{77}$. Igualmente, $\mathrm{Zhu}$ et al. afirman que al combinar chitosan con otro andamio conduce a la disminución de la inflamación y la inhibición concomitante de Streptococcus mutans y el crecimiento de Lactobacillus casei. $^{78}$

En ese sentido, Zein concluye que los hidrogeles a base de polímeros naturales y sintéticos son materiales apropiados para la regeneración de la pulpa dental, ya que constituyen andamios viscosos, flexibles e inyectables, donde se puede controlar la cantidad y el tamaño de los poros y agregar antibióticos y antioxidantes. ${ }^{77}$

\section{Conclusiones}

La endodoncia regenerativa representa un nuevo avance en la endodoncia biológica y clínica. Actualmente, este es el procedimiento de base biológica que está siendo reconocido como la primera opción de tratamiento para dientes inmaduros con necrosis pulpar basada en el éxito de muchos casos publicados en la literatura.

La meta en los PRE sería desarrollar andamios de última generación que imiten la matriz extracelular, de bajo costo y fácil obtención, entre ellas, las nuevas tendencias como L-FRP y A-FRP han alcanzado muy buenos resultados, ya que liberan mayor cantidad de plaquetas y factores de crecimiento, son de fácil preparación, 
presentan un mejor comportamiento del linaje fagocítico, disminuyen edema y dolor postoperatorio.

La adición de un andamio secundario a la matriz principal es necesario en ciertos casos con el fin de potenciar y conseguir una mejor adhesión, migración, proliferación y diferenciación celular.

\section{Referencias}

1. Jadhav G, Shab N, Logani A. Revascularization with and without Plateletrich plasma in nonvital, inmature, anterior teeth: A pilot clinical study. J Endod. 2012; 38 (12): 1581-7.

2. Vidal K, Martin G, Lozano O, Salas M, Trigueros J. Apical closure in apexification: A review and case report of apexification treatment of an immature permanent tooth with biodentine. J Endod, 2016; 42(5):730-4.

3. Kim SG, Malek M, Sigurdsson A, Lin LM, Kahler B. Regenerative endodontics: a comprehensive review. Int Endod J. 2018; 51: $1367-88$.

4. Glossary of endodontic terms. 9th ed. Chicago: American Association of Endodontists; 2015.

5. Botero $T$, Norr J. Tissue Engineering Strategies for Endodontic regeneration. USA:Elsevier; 2015.

6. Hashemi-Benia B, Khoroushib M, Foroughic M, Karbasid S, Khademi A. Tissue engineering: Dentin - pulp complex regeneration approaches (A review). Tissue cell. 2017; 49(5):552-64.

7. Camargo P, Rojas H. Revascularización pulpar mediante la utilización de plasma rico en plaquetas autólogo o en combinación con una matriz colágena, como posibilidades terapéuticas para dientes con ápice abierto, pulpa necrótica $\mathrm{y} / \mathrm{o}$ patología periapical: revisión narrativa de la literatura. Acta
Odontológica Colombiana. 2014; 4 (1): 11329.

8. Chrepa V. Regenerative Endodontic Therapy: A Treatment With Substantial Benefits. AAE. 2016.

9. Méndez V, Madrid K, Amador E, SilvaHerzog D, Rodríguez R. Revascularización en dientes permanentes con ápice inmaduro $\mathrm{y}$ necrosis pulpar: Revisión bibliográfica. Rev ADM 2014; 71 (3): 110-4.

10. Fernández J, Maresca $\mathrm{B}$, Fernández E. Apicoformación en dientes permanentes jóvenes. RAAO. 2014; 52 (1): 29-35.

11. Lambrichts I, Driesen R, Dillen Y, Gervois P, Ratajczak J, Vangansewinkel T, Wolfs E, Bronckaers A, Hilkens P. Dental Pulp Stem Cells: Their Potential in Reinnervation and Angiogenesis by Using Scaffolds. J Endod. 2017; 43(9):12-6.

12. Bakhtiar H, Mazidi A, Asl S, Ellini M, Moshiri A, Dummer P. The role of stem cell therapy in regeneration of dentine-pulp complex: a systematic review. Prog Biomater. 2018; 7(4):249-68.

13. Vishwakarma A, Sharpe P, Ramalingam S. Stem Cell Biology and Tissue Engineering in Dental Sciences. $1^{\text {a }}$ ed. USA: Elsevier; 2014.

14. Caicedo C, Villareal $M$. Avances en bioingeniería dental y su aplicación en ortodoncia y ortopedia dentofacial: Una revisión de literatura. Rev Estomatol. 2017; 25 (1): 32-42.

15. Duncan H, Kobayashi Y, Shimizu E. Growth Factors and Cell Homing in Dental Tissue Regeneration. Curr Oral Health Rep. 2018; 5(4):276-85.

16. Arai F, Hirao A, Ohmura M, Sato $H$, Matsuoka S, Takubo K. Tie2/angiopoietin-1 signaling regulates hematopoietic stem cell quiescence in the bone marrow niche. Cell. 2004; 118(2):149-61.

17. Wang J, Mukaida N, Zhang Y, Ito T, Nakao $\mathrm{S}$, Matsushima K. Enhanced mobilization of 
hematopoietic progenitor cells by mouse MIP-2 and granulocyte colony-stimulating factor in mice. J Leukoc Biol. 1997; 62: 5039.

18. Zeng Q, Nguyen S, Zhang H, Chebrolu H, Alzebdeh D, Badi M, Kim J, Ling J, Yang M. Release of growth factors into root canal by irrigations in regenerative endodontics. $\mathrm{J}$ Endod. 2016; 42:1760-66.

19. Tronci G. Synthesis, Characterization, and Biological Evaluation of Gelatin-based Scaffolds. Potsdam: Universidad de Potsdam Alemania; 2010.

20. Anitua E, Troya M, Zalduendo M. Progress in the use of dental pulp stem cells in regenerative medicine. Cytotherapy, 2018; 20(4):479-98.

21. Gathani K, Raghavendra S. Scaffolds in regenerative endodontics: A review. Dent Res J. 2016; 13:379-86.

22. Raju S, Yadav S, Kumar S. Revascularization of immature mandibular premolar with pulpal necrosis - a case report. J Clin Diagn Res. 2014; 8(9):29-31.

23. Lin Y, Huang S, Zou R, Gao X, Ruan J, Weir M, Reynolds M, Qin W, Chang X, Fu H, Xu H. Calcium phosphate cement scaffold with stem cellco-culture and prevascularization for dental and craniofacial bone tissue engineering. Dent Mat. 2019; 35(7):1031-41.

24. Kuang R, Zhang Z, Jin X, Hu J, Shi S, Ni L, Ma PX. Nanofibrous spongy microspheres for the delivery of hypoxia-primed human dental pulp stem cells to regenerate vascularized dental pulp. Acta Biomater. 2016; 33:225-34.

25. Bezgin T, Yilmaz A, Celik B, Kolsuz M, Sonmez H. Efficacy of Platelet-rich plasma as a scaffold in regenerative endodontic treatment. J Endod. 2015; 41(1):36-44.

26. Martin G, Ricucci D, Gibbs J, Lin L. Histological Findings of Revascularized/Revitalized Immature
Permanent Molar with Apical Periodontitis Using Platelet-rich Plasma. J Endod. 2013; 39 (1): 138-44.

27. Zhang K, Wang S, Zhou C, Cheng L, Gao X, Xie X, Sun J, Wang H, Weir M, Reynolds M, Zhang N, Bai, Xu H. Advanced smart biomaterials and constructs for hard tissue engineering and regeneration. Bone Res. 2018; 6 (31):1-15.

28. Jiang $X$, Liu $H$, Peng $C$. Clinical and Radiographic Assessment of the Efficacy of a Collagen Membrane in Regenerative Endodontics: A Randomized, Controlled Clinical Trial. J Endod. 2017; 43 (9): 146771.

29. Suresh N, Arul B, Kowsky D, Natanasabapathy V. Successful Regenerative Endodontic Procedure of a Nonvital Immature Permanent Central Incisor Using Amniotic Membrane as a Novel Scaffold. Dent J. 2018; 6(3): 1-8.

30. Chandra A, Yadav R, Yadav S. Scaffold based Regenerative Endodontics: Present \& future. Saudi J. Oral. Dent. Res. 2016; 1(2): $37-41$.

31. Ghosh M, Halperin-Sternfeld M, Grinberg I, Adler-Abramovich L. Injectable AlginatePeptide Composite Hydrogel as a Scaffold for Bone Tissue Regeneration. Nanomaterials. 2019; 9(4): 1-15.

32. Buurma B, Gu K, Rutherford RB. Transplantation of human pulpal and gingival fibroblasts attached to synthetic scaffolds. Eur J Oral Sci 1999; 107: 282-9.

33. Chen, Y.J.; Chung, M.C.; Yao, C.C.; Huang, C.H.; Chang, H.H.; Jeng, J.H.; Young, T.H. The effects of acellular amniotic membrane matrix on osteogenic differentiation and ERK1/2 signaling in human dental apical papilla cells. Biomaterials. 2012; 33: 455-63.

34. Conte R, Di Salle A, Riccitiello F, Petillo O, Peluso G, Calarco A. Biodegradable polymers in dental tissue engineering and 
regeneration. AIMS Mater Sci. 2018; 5(6): 1073-101.

35. Lee LW, Hsiao SH, Lin YH, Chen PY, Lee YL, Hung WC. Outcomes of necrotic immature open-apex central incisors treated by mta apexification using poly ( $\varepsilon-$ caprolactone) fiber mesh as an apical barrier. J Formos Med Assoc. 2019; 118:362-70.

36. Alshehadat S, Thu H, Hamid S, Nurul A, Rani S, Ahmad A. Scaffolds for dental pulp tissue regeneration: A review. Int Dent Med J Adv Res. 2016; 2: 1-12.

37. Devillard R, Rémy M, Kalisky J, Bourget JM, Kérourédan O, Siadous R, Bareille R, Amédée-Vilamitjana J, Chassande O, Fricain $\mathrm{JC}$. In vitro assessment of a collagen/alginate composite scaffold for regenerative endodontics. Int Endod J. 2017; 50(1):48-57.

38. Silva CR, Babo PS, Gulino M, Costa L, Oliveira JM, Silva-Correia J, Domingues RMA, Reis RL, Gomes ME. Injectable and tunable hyaluronic acid hydrogels releasing chemotactic and angiogenic growth factors for endodontic regeneration. Acta Biomater. 2018; 77:155-71.

39. Taghipour YD, Hokmabad VR, Del Bakhshayesh AR, Asadi N, Salehi R, Nasrabadi HT. The application of hydrogels based on natural polymers for tissue engineering. Curr Med Chem. 2019; 14: 5303-21.

40. Gaviño J, Caviedes J, Manzanares M, Berastegui E, Biedma B, Segura J, López J. Use of platelet-rich plasma in Endodontic procedures in adults: Regeneration or repair? A report of 3 cases with 5 years of follow-up. J Endod. 2017; 43 (8): 1294-1301.

41. Anantula K, Annareddy A. Platelet-rich fibrin (PRF) as an autologous biomaterial after an endodontic surgery: Case reports. J NTR Univ Health Sci. 2016; 5(1): 49-54.

42. He X, Chen W, Ban G, Wei W, Zhou J, Chen W, Li X. A New Method to Develop Human
Dental Pulp Cells and Platelet-rich Fibrin Complex. J Endod. 2016; 42 (11):1633-40.

43. Dohan D, Choukroun J, Diss A, Dohan S, Dohan A, Mouhyi J, Gogly B. Platelet-rich fibrin (PRF): A second-generation platelet concentrate. Part I: Technological concepts and evolution. Oral Surg Oral Med Oral Pathol Oral Radiol Endod. 2006; 101(3): 3744.

44. Orión A, Salgado A, Arriba L. Nuevas tendencias en regeneración tisular: fibrina rica en plaquetas y leucocitos. Rev esp cir oral maxilofac. 2017; 39(2):91-8.

45. Khiste SV, Tari RN. Platelet-rich fibrin as a biofuel for tissue regeneration. Int Sch Res Notices. 2013; 1-6.

46. Sameera S, Nagasri M, Kumar P, Indeevar P, Raviraj K, Musalaiah S. Comparison of two surgical techniques in the treatment of multiple gingival recessions sandwiched with a combination of A-PRF and L-PRF. Saudi Dent J. 2018; 30(3):183-9.

47. Kobayashi E, Flückiger L, Kobayashi M, Sawada K, Sculean A, challer B, Miron R. Comparative release of growth factors from PRP, PRF, and advanced-PRF. Clin Oral Invest. 2016; 20(9):1-8.

48. Steller D, Herbst N, Pries R, Juhl D, Hakim SG. Impact of incubation method on the release of growth factors in Non-Ca2+ activated PRP, Ca2+ - activated PRP, PRF and A-PRF.J Craniomaxillofac Surg. 2018; 47(2):365-72.

49. Banchs F, Trope M. Revascularization of immature permanent teeth with apical periodontitis: new treatment protocol? J Endod. 2004; 30(4):196-200.

50. Wigler R, Kaufman A, Lin S, Steinbock N, Hazan-Molina H, Torneck C. Revascularization: a treatment for permanent teeth with necrotic pulp and incomplete root development. J Endod. 2013; 39(3):319-26. 
51. Nosrat A, Kolahdouzan A, Khatibi A, Verma P, Jamshidi D, Nevins A, Torabinejad M. Clinical, Radiographic, and Histologic Outcome of Regenerative Endodontic Treatment in Human Teeth Using a Novel Collagen-hydroxyapatite Scaffold. J Endod. 2019; 45:136-43.

52. Lenzi R, Trope M. Revitalization procedures in two traumatized incisors with different biological outcomes. J Endod. 2012; 38:4114.

53. Namour M, Theys S. Pulp revascularization of immature permanent teeth: a review of the literature and a proposal of a new clinical protocol. ScientificWorldJournal. 2014; 2014: 1-9.

54. Facchin C, D’Anselmo G, Jiménez L. Procedimiento endodóntico regenerativo en diente permanente no vital con ápice inmaduro. Reporte de caso. Odous científica. 2018; 19(1):29- 41.

55. Ding RY, Cheung GS-P, Chen J, Yin XZ, Wang QQ, Zhang CF. Pulp revascularization of immature teeth with apical periodontitis: a clinical study. J Endod. 2009; 35(5):745-9.

56. Cehreli ZC, Isbitirin B, Sara S, Erbas G. Regenerative endodontic treatment (revascularization) of immature necrotic molars medicated with calcium hydroxide: a case series. J Endod. 2011; 37(9): 1327-30.

57. Mc Cabe. Revascularization of an immature tooth with apical periodontitis using a single visit protocol: a case report. Int Endod J. 2014; 48(5):484-97.

58. Ulusoy A, Turedi I, Cinem M, Cebreli Z. Evaluation of blood clot, platelet rich plasma, platelet rich fibrin, and platelet pellet as scaffolds in regenerative endodontic treatment: A prospective randomized trial. J Endod. 2019; 45(5): 560-6.

59. Jung IY, Lee SJ, Hargreaves KM. Biologically based treatment of immature permanent teeth with pulpal necrosis: a case series. J Endod 2008; 34(7): 876-87.

60. Chan G, Mooney DJ. New materials for tissue engineering: towards greater control over the biological response. Trends Biotechnol. 2008; 26(7): 382-92.

61. Galler KM, D'Souza RN, Hartgerink JD, Schmalz G. Scaffolds for dental pulp tissue engineering. Adv Dent Res. 2011; 23: 333-9.

62. Petrino JA, Boda KK, Shambarger S, Bowles WR, McClanahan SB. Challenges in regenerative endodontics: a case series. J Endod. 2010; 36(3): 536-41.

63. Diogenes A, Henry MS, Teixiera F, Hargreaves K. An update on clinical regenerative endodontics. Endodontic Topics. 2013; 28: 2-23.

64. Moyetones L, Zavarce S. Revascularización en dientes permanentes inmaduros. Estado del Arte. Oral. 2018; 19(60): 1615-9.

65. Torabinejad M, Faras H. A Clinical and Histological Report of a Tooth with an Open Apex Treated with Regenerative Endodontics Using Platelet-rich Plasma. J Endod. 2012; 38:864-8.

66. Shah R, M G T, Thomas R, Mehta DS. An Update on the Protocols and Biologic Actions of Platelet Rich Fibrin in Dentistry. Shah Eur J Prosthodont Restor Dent. 2017;25(2):64-72.

67. Gassling V, Douglas T, Warnke PH, Acil Y, Wiltfang J, Becker ST. Platelet-rich fibrin membranes as scaffolds for periosteal tissue engineering. Clin Oral Implants Res. 2010; 21:543-9.

68. Zhou R, Wang Y, Chen Y, Chen S, Lyu H, Cai Z, Huang X. Radiographic, Histologic, and Biomechanical Evaluation of Combined Application of Platelet-rich Fibrin with Blood Clot in Regenerative Endodontics. J Endod. 2017; 43: 1-7.

69. Miron RJ, Fujioka-Kobayashi M, Bishara M, Zhang Y, Hernandez M, Choukroun J. 
Platelet-rich fibrin and soft tissue wound healing: a systematic review. Tissue Eng Part B Rev. 2017; 2(1):83-99.

70. Dragonas P, T. Katsaros, G. Avila-Ortiz, L. Chambrone, J.H. Schiavo, A. Palaiologou. Effects of leukocyte-platelet-rich fibrin (LPRF) in different intraoral bone grafting procedures: a systematic review. Int. J. Oral Maxillofac. Surg. 2018; 48(2):250-62.

71. Crisci A, Manfredi S, Crisci M. The L-PRF Membrane (Fibrin Rich in Platelets and Leukocytes) And Its Derivatives Useful as A Source of Stem Cells in Wound Surgery. J Stem Cell Rep. 2019; 101 (1): 1-11.

72. Ajay Sharma L, Sharma A, Dias GJ. Advances in regeneration of dental pulp - a literature review. J Investig Clin Dent. 2013; 6(2):85-98.

73. Ghanaati S, Booms P, Orlowska A, Kubesch A, Lorenz J, Rutkowski J, Landes C, Sader R, Kirkpatrick CJ, Choukroun J. Advanced Platelet-Rich Fibrin: A New Concept for Cell-Based Tissue Engineering by Means of Inflammatory Cells. J Oral Implantol. 2014; 11(6): 679-89.

74. Kim JJ, Bae WJ, Kim JM, Kim, JJ, Lee EJ, Kim HW, Kim E.C. Mineralized polycaprolactone nanofibrous matrix for odontogenesis of human dental pulp cells. J. Biomater. Appl. 2014; 28:1069-78.

75. Keller L, Offner D, Schwinté P, Morand D, Wagner Q, Gros C, Bornert F, Bahi S, Musset AM, Benkirane-Jessel N. Active Nanomaterials to Meet the Challenge of Dental Pulp Regeneration. Materials (Basel). 2015; 8(11): 7461-71.

76. Bolaina E. Estudio de la relación estructurapropiedades en andamios electrohilados hechos a base de quitosano $y$ policaprolactona para su posible uso en ingeniería de tejidos de nervio periférico. Yucatán: Centro de Investigación Científica de Yucatán; 2016.

77. Zein N, Harmouch E, Lutz J, De Grado G, Kuchler-Bopp S, Clauss F, Offner D, Hua G, Benkirane-Jessel N, Fioretti F. PolymerBased Instructive Scaffolds for Endodontic Regeneration. Materials. 2019; 12(2347): 118.

78. Zhu N, Chatzistavrou X, Ge L, Qin M, Papagerakis P, Wang Y. Biological properties of modified bioactive glass on dental pulp cells. J. Dent. 2019; 83: 18-26. 